\title{
Investigating the Interaction between Asphalt Binder and Fresh and Simulated RAP Aggregate
}

\author{
Meng Guo ${ }^{I}$, Ph.D. \\ Assistant Professor \\ National Center for Materials Service Safety, \\ University of Science and Technology Beijing \\ School of Transportation Science and Engineering, \\ Harbin Institute of Technology \\ Department of Civil, Architectural and Environmental Engineering, \\ The University of Texas at Austin \\ Email:mguo@ustb.edu.cn

\section{Arash Motamed, Ph.D.} \\ Assistant Professor \\ Department of Civil Engineering \\ Sharif University of Technology \\ Azadi St., Tehran, Iran \\ Researcher, Center for Transportation Research, \\ The University of Texas at Austin \\ Email:aramtm@gmail.com
}

Yiqiu Tan, Ph.D.

Professor

School of Transportation Science and Engineering,

Harbin Institute of Technology,

73 Huanghe Road, Nangang District,

Harbin, Heilongjiang 150090, China

Email:tanyiqiu@hit.edu.cn

\section{Amit Bhasin, Ph.D.}

Associate Professor

Department of Civil, Architectural and Environmental Engineering,

The University of Texas at Austin

301 E. Dean Keeton St., Stop C1747,

Austin, TX 78712-0273, United States

Email:a-bhasin@mail.utexas.edu

1- Corresponding author 


\begin{abstract}
Although the role of individual ingredients of hot mix asphalt (HMA) such as asphalt binder and aggregates on its performance is readily recognized, there is only limited understanding about the interactions between these components and the properties of binder-aggregate interface. In order to study the interactions between asphalt binder and mineral aggregates, an interfacial test method was developed and its effectiveness was evaluated. Interfacial interactions were evaluated by testing thin films of an asphalt binder interfaced with the surface of aggregates under two different modes of loading in shear: sinusoidal oscillation and monotonically increasing. An Interaction Parameter (IP) was proposed to quantify the binder-aggregate interfacial effects. The results show that the methodology used in this study can quantify the effects of interaction between the asphalt binder and mineral aggregates. Furthermore, this research also investigated the interaction of an asphalt binder with the surface of simulated reclaimed asphalt pavement (RAP) aggregates. The results from this research not only provide an insight to the effects of binder-aggregate interaction, but can also help practitioners to better understand the effect of mixing conditions on the properties of mixtures produced using different materials.
\end{abstract}

\title{
KEY WORDS
}

Asphaltic materials; Reclaimed asphalt pavement; Interfacial interaction; Annular test geometry; Mixing conditions. 


\section{INTRODUCTION}

\section{Background and Motivations}

Asphalt mixtures are composed of asphalt binder, mineral aggregates, and air voids. The properties of asphalt binder and mineral aggregates, as well as the air void distribution within the mixture dictate the properties and performance of the mixture. The role of individual ingredients such as the asphalt binder and aggregates on mixture performance is readily known. The relevance of binder-aggregate interaction to mixture performance is also recognized in the literature [1-5]. For instance, investigations on the mechanisms of adhesive failure show that these types of failures are significantly influenced by the characteristics of the binder-aggregate interface [6-9]. However, the effect of the interfacial interactions on the properties of the binder in the vicinity of the interface is not well established. Considering the large specific surface area of mineral aggregates in an asphalt mixture, these effects cannot be undermined. Furthermore, with an increasing emphasis on the use of reclaimed asphalt pavement (RAP), there is a renewed interest in better understanding the influence of binder interactions with fresh aggregates and black rock on the properties of the binder and the mixture [10-12].

Several approaches have been used in the past to better understand the interactions at the binder-aggregate interface as well as the effect of these interactions on the properties of asphalt mixtures. These approaches can be categorized in two main groups: (i) measuring properties related to thermodynamics, and (ii) mechanical methods. For example, Bhasin used surface free energy methods to quantify the interfacial adhesion between asphalt binder and mineral aggregates, and analyze the effect of water on loss of adhesion [6]. Ghabchi et al. used the same approach to evaluate the moisture susceptibility of asphalt mixes containing RAP [13]. Tan and Guo used the surface free energy method to study the cohesion and adhesion of asphalt mastic, and explored the influence of filler types and moisture [14]. Wei et al. studied the relationship between surface free energy and chemical composition of asphalt binder, and used this to explain why surface free energy method is an efficient tool to quantify the interaction [15]. Tan and Guo studied the relationship between surface free energy and conventional metrics quantifying moisture resistance of asphalt mixture (such as the freeze-thaw splitting test and the pull-off test) for cold mix asphalt, and demonstrated that there is good correlation between macro mechanical indicators and energy indices [5]. Clopotel et al. used a thermodynamics method to measure physico-chemical interaction in mastics based on glass transition [16]. Recently, Tan and Guo calculated the interface thicknesses between asphalt binder and mineral fillers by measuring the changes in specific heat during the glass transition [17].

In the context of using mechanical methods to characterize the interfacial interactions, Taylor used dynamic mechanical analysis to study surface interaction between binder and mineral fillers, and their effects on the rheology of bitumen-filler mastics. He proposed that reciprocal critical volume fraction can be used to quantify the interfacial interaction between asphalt and filler [18]. Later, Tan and Guo proposed an interaction parameter to quantify the 
interaction between the asphalt binder and mineral fillers based on a modified form of the Palierne emulsion model [17]. In addition, they used dynamic mechanical analysis to study the interfacial phase separation phenomenon in asphalt mastic, and analyzed the effect of temperature and filler types [19].

Various characterization techniques were used to qualitatively study the interaction mechanism between asphalt binder and mineral aggregate (including RAP Aggregate). For instance, Ribeiro et al. found that the chemical interaction between minerals and asphalt binder affects the performance of asphalt mixtures [20]. Later, Horgnies et al. investigated the influence of the interfacial composition on the adhesion between aggregates and binder by conducting Energy Dispersive X-ray (EDX), X-ray Photoelectron Spectroscopy (XPS), and peel tests [21]. Recently, Davis and Castorena used Atomic Force Microscopy (AFM) to investigate the effects of physico-chemical interaction on binder matrix microstructure, and to qualitatively relate microstructure to macroscopic rheology [22]. To study the blending and interactions in RAP mixtures, Mohajeri et al. studied the interfacial zone between reclaimed asphalt binder and virgin binder using nano-indentation, nano-computed tomography, and optical microscopy [11]. In addition, Rinaldini et al. used rheology, electron microscopy, and computer tomography to investigate the blending of reclaimed asphalt with virgin binder. They found that the blending in their study was not homogeneous throughout the sample. Some locations showed good blending whereas other locations appeared non-blended with micro-cracks forming at the binder boundaries [23].

Although previous studies have created a better understanding of the interactions at binder-aggregate interface, there are still two main shortcomings that need to be further investigated. First, most of the previous investigations were qualitative and the limited quantitative studies were mostly focused on estimating the influence of interactions in the mastic as a continuum, comprising of binder and mineral fillers. Second, limited work has been done to evaluate the impact of these interactions on the behavior of the binder in the vicinity of such interfaces. The effect and importance of these interactions on mixture performance needs to be quantitatively investigated.

Understanding the influence of interactions at the binder-aggregate interface on the properties of the binder is particularly important in the context of warm mix asphalt (WMA) with RAP. The use of WMA technologies with mixes containing RAP has significantly increased in recent years to reduce construction costs and environmental issues. Several studies have reported an increase in the use of a WMA with RAP in lieu of the conventional hot mix asphalt (HMA) [24-25]. However, some researchers have reported issues with WMA containing high percentage of RAP. These studies demonstrated that WMA mixtures with RAP might have low moisture, rutting, and thermal cracking resistance [26-28]. It has been speculated that improper blending of the virgin binder with the aged binder coating the RAP aggregate surface at lower WMA temperatures can result in reduced durability.

\section{Scope}

The first objective of this research was to develop a tool to investigate the effect of binder-aggregate interactions on the binder properties. The second objective was to use this 
tool to investigate (i) the effect of aggregate type, conditioning time, and conditioning temperature on the binder properties in vicinity of the binder - aggregate interface, and (ii) the effect of curing time and temperature on the binder properties in the vicinity of the interface between a virgin binder and the surface of a laboratory simulated RAP aggregate. The findings from this study help provide a guide for optimizing time and temperature for mixing and compaction of asphalt mixtures with RAP.

\section{Definitions}

Note that the definition of what constitutes an interface in an asphalt - aggregates system can be somewhat ambiguous, let alone an attempt to quantify the properties of such an entity. However, from an engineering standpoint, the properties of the binder immediately beyond the aggregate surface are of more interest. Specifically, the focus of this study is to understand the influence of the interactions that occur between the binder and an aggregate surface on the properties of the binder. For this reason, in the context of this paper, the term "effect of binder-aggregate interactions", refers to the effect of binder-aggregate interactions on the properties of the binder in the vicinity of the interface. The term "fresh aggregate" is used to refer to an aggregate that used in specimen preparation without any prior exposure to the asphalt binder. Also, the term "RAP aggregates" is used to refer to an aggregate with an aged asphalt film. These aged asphalt covered aggregate surfaces were intended to simulate the surface of a black rock that interacts with virgin binder as in the case of a mix incorporating RAP with virgin binder. A detailed procedure used to make simulated RAP aggregates in the laboratory is discussed in the subsequent sections.

\section{LABORATORY TESTING}

This section describes the materials and test methods that were used in this study. This section also includes specimen fabrication and conditioning used in this research to measure the interaction of an asphalt binder with fresh and laboratory simulated RAP aggregates.

\section{Test Materials}

The asphalt binder used in this research had a Performance Grade (PG) of 64-22. To investigate the effect of aggregate type on the binder - aggregate interaction, two different types of aggregates were selected that are commonly used in the road construction: limestone and granite. To study the interaction of asphalt binder with RAP aggregates, limestone aggregates were used to artificially produce RAP aggregate surfaces. This will be further described in the following sections.

\section{Specimen Fabrication and Conditioning}

A new geometric configuration was developed to investigate the binder - aggregate interactions. This configuration comprised of an annular specimen of asphalt binder bounded concentrically between an aggregate surface on the outside and a steel rod on the inside (Figure 1-a). To prepare test specimens the following procedure was used. 
First, coarse particles of the mineral aggregates were cut using a diamond saw to obtain $10 \mathrm{~mm}$ thick slices. The cuts were only done to create two flat and parallel surfaces. Second, the prepared aggregate was adhered on the top of the steel pedestal (Figure 1-c). Third, the steel rod and the steel pedestal with aggregate were installed on the Instron E1000, followed by closing the top and bottom chucks until the steel rod came into contact with the aggregate surface. The contact point was carefully marked and all parts were removed from the Instron E1000. Then, a $6 \mathrm{~mm}$ hole with the marked point as the center was drilled using a machine mounted precision drill through the sliced aggregates, perpendicular to the parallel flat surfaces.

To prepare the test specimen, the asphalt binder was heated to $160^{\circ} \mathrm{C}$ and poured into this hole. Next, a steel rod of $4.8 \mathrm{~mm}$ diameter was inserted into the hole. The steel rod and aggregate were preheated to $160^{\circ} \mathrm{C}$. To create an annular specimen, the authors used silicon to separate the base of the rod from the metal substrate, preventing the rod from adhering to the substrate. This was done by placing one silicon pad in the center of the steel substrate and another one at the bottom of the steel rod in advance (Figure 1-c). In order to ensure that the asphalt film is uniform with a thickness of $0.6 \mathrm{~mm}$, an aluminum frame with a hole of 4.8 $\mathrm{mm}$ diameter was used to keep the steel rod vertically aligned in the center. Finally, the entire assembly (including aggregate, binder, steel rod, and aluminum frame) was placed in the oven at a temperature of $160^{\circ} \mathrm{C}$ for 1 hour to make sure the asphalt binder and aggregate completely bonded and there was no air trapped in the specimen. The choice of the $0.6 \mathrm{~mm}$ thick annular ring specimen was intended to measure the influence of binder-aggregate interaction on the bulk properties of the binder in the immediate vicinity of the interface. As such, the thickness of the annular ring will influence the sensitivity of the binder properties to the interactions taking place at the interface; smaller thickness would increase the sensitivity of the results to the interaction. The choice of $0.6 \mathrm{~mm}$ thickness in this case was made to ensure that the thickness was as small as possible but still much larger than the machining and alignment tolerances of the equipment.

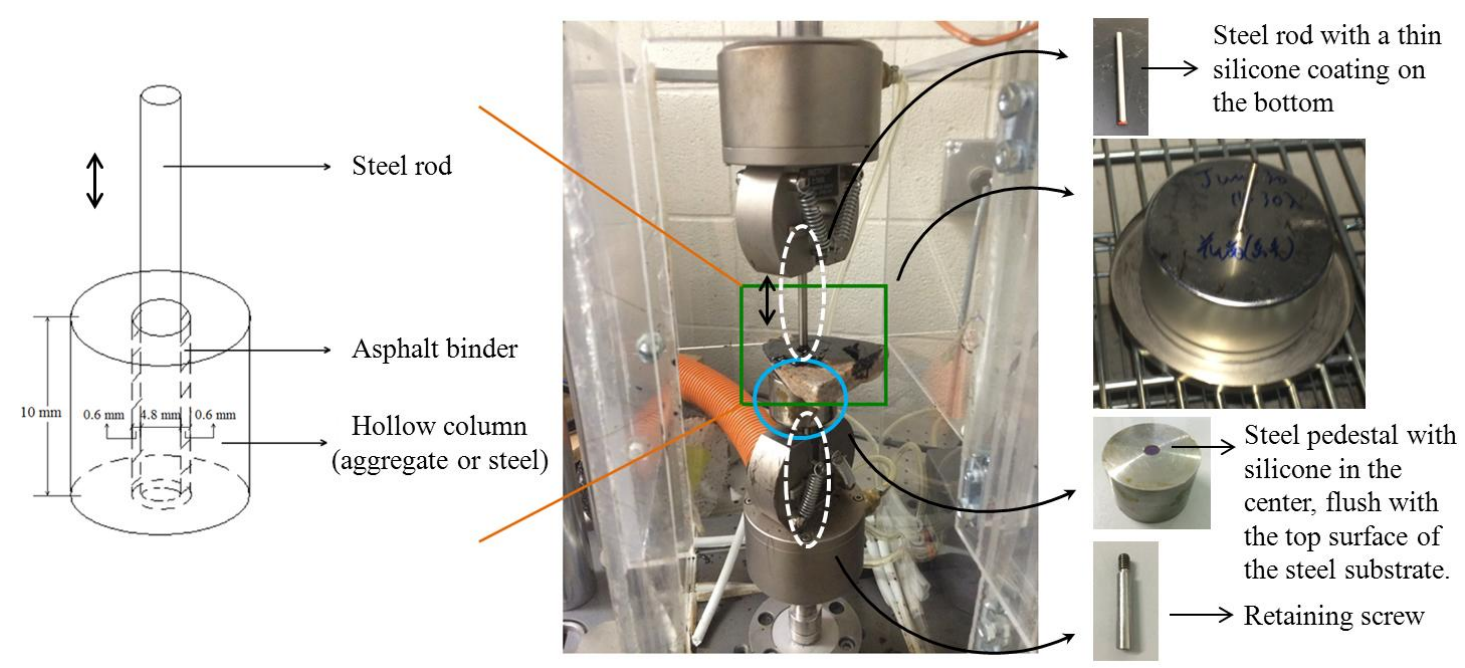

(a) Schematic of test geometry

(b) Test set up

(c) Testing fixture components

FIGURE 1 Test set up for evaluating the interaction between asphalt binder and aggregate. 
To examine the binder - aggregate interactions over time after construction, the specimens were conditioned at an elevated temperature for different durations of time. Conditioning was done by placing the entire configuration in an oven at $60^{\circ} \mathrm{C}$ for $0,2,10$, and 35 days. Conditioning at $60^{\circ} \mathrm{C}$ was to accelerate the interaction between the aggregate and binder, if any. In order to be able to differentiate the effect of aging and the effect of potential interfacial interactions over time, the authors used control specimens that were fabricated using $10 \mathrm{~mm}$ thick steel plates instead of aggregate slices. This was based on the assumption that the interaction between binder and steel, if any, would occur instantaneously and it would not change with time at a constant temperature. It is important to point out that the choice of the annular ring geometry was to allow the binder to remain in contact with the aggregate surface as it was being conditioned for prolonged durations of time. The use of traditional disc like geometry, such as those used with the dynamic shear rheometer (DSR), causes the binder to flow and distort the geometry [29].

In order to investigate the interaction between asphalt binder and RAP aggregates, limestone aggregates were used to produce simulated RAP aggregates. RAP aggregates from reclaimed asphalt are coated with a film of an aged asphalt binder. To artificially produce these simulated RAP aggregate surfaces, the coarse aggregate particles were sliced and a 6 $\mathrm{mm}$ hole was drilled in middle (Figure 2-a). The hole was filled with an asphalt binder at $160^{\circ} \mathrm{C}$ (Figure 2-b). The aggregate with the binder filled in it was conditioned in an oven at $160^{\circ} \mathrm{C}$ for 12 hours to accelerate any interaction between the binder and the aggregate interface. After this, the excess binder was poured out of the hole leaving a thin coating of the binder on the inside of the hole (Figure 2-c). The aggregates coated with this thin film of asphalt were then allowed to further oxidize to simulate an aged RAP aggregate surface. Aging was conducted by placing the coated aggregates in a convection oven at $60^{\circ} \mathrm{C}$ for 35 days, followed by cooling at room temperature for 24 hours. These artificial RAP aggregates were then was adhered to a steel substrate to carry out the tests as before.

To investigate the effect of mixing time and temperature on binder - RAP aggregate interaction, the specimens were cured using different conditions. Instead of curing at $160^{\circ} \mathrm{C}$ for one hour, as was the case for the fresh aggregates, these specimens were prepared at 4 different temperatures $\left(110,130,145\right.$, and $\left.160^{\circ} \mathrm{C}\right)$ and cured for different durations of time (1, 2 , and 5 hours). This was done to evaluate the influence of mixing time and temperature on blending of fresh and aged asphalt binders.

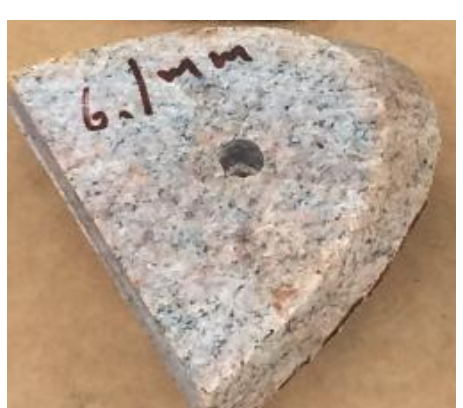

(a) Slicing and drilling

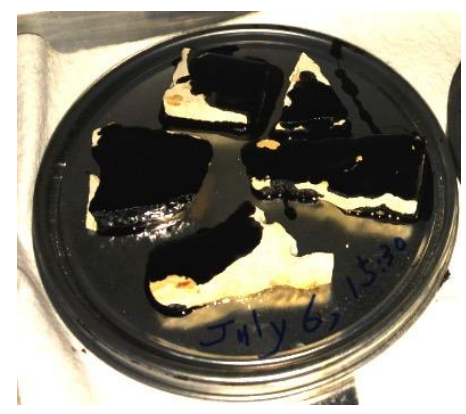

(b) Interaction process

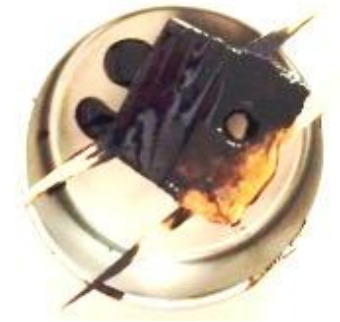

(c) Aging simulation

FIGURE 2 The procedure used to simulate RAP aggregates in the laboratory. 


\section{Laboratory Test Methods}

The specimens were tested under two different modes of loading in shear: sinusoidal oscillation and monotonically increasing. This section presents the details on the test procedures used in this study.

All tests were conducted using a tension-compression dynamic mechanical analyzer (DMA- Model Instron ElectroPuls E1000). As demonstrated in Figure 1, the specimen is held in place by the lower grip, and a shear stress was applied to the interface by axial displacement of the steel rod. All tests were conducted at intermediate temperatures, $15^{\circ} \mathrm{C}-25^{\circ} \mathrm{C}$. The test temperatures were well above the glass transition temperature $\left(T_{g}\right)$ of asphalt binders; which typically ranges from $-30^{\circ} \mathrm{C}$ to $-5^{\circ} \mathrm{C}$.

The oscillatory shear test was conducted in the strain-controlled mode with a strain-amplitude of $8.3 \%$. The complex shear modulus of the binder, $\left|G^{*}\right|$ was calculated by dividing the measured stress amplitude $\tau_{\max }$ by the applied strain amplitude $\gamma_{\max }$ :

$$
\left|G^{*}\right|=\frac{\tau_{\max }}{\gamma_{\max }}
$$

The complex shear modulus was used to estimate the degree of interaction that will be explained in the next section. To examine the effect of test conditions (temperature and loading rate) on the effect of binder-aggregate interaction, this test was conducted at 3 different temperatures $\left(15,20\right.$, and $\left.25^{\circ} \mathrm{C}\right)$ and 3 different frequencies $(0.1,1$, and $5 \mathrm{~Hz})$. In this research, at least three replicates were selected for each test under the same set of conditions.

In order to measure the bonding shear strength or performance of the interface, specimens were tested under a monotonically increasing load at $20^{\circ} \mathrm{C}$. This test, which is also referred to as the direct pull-off test, was conducted in displacement-controlled mode at a rate of $1 \mathrm{~mm} / \mathrm{s}$. In this test, displacement linearly increased with time until the separation or fracture at interface occurred, and the nominal stress in the binder was measured. The fracture properties of the near interface binder were evaluated using the stress-strain curves derived from this test. Figure 3 illustrates a typical test result obtained from direct pull-off test under monotonic loading. For the purposes of this study, the peak of the stress-strain curve, referred to as the bonding shear strength, was used as an indicator of interfacial shear performance. 


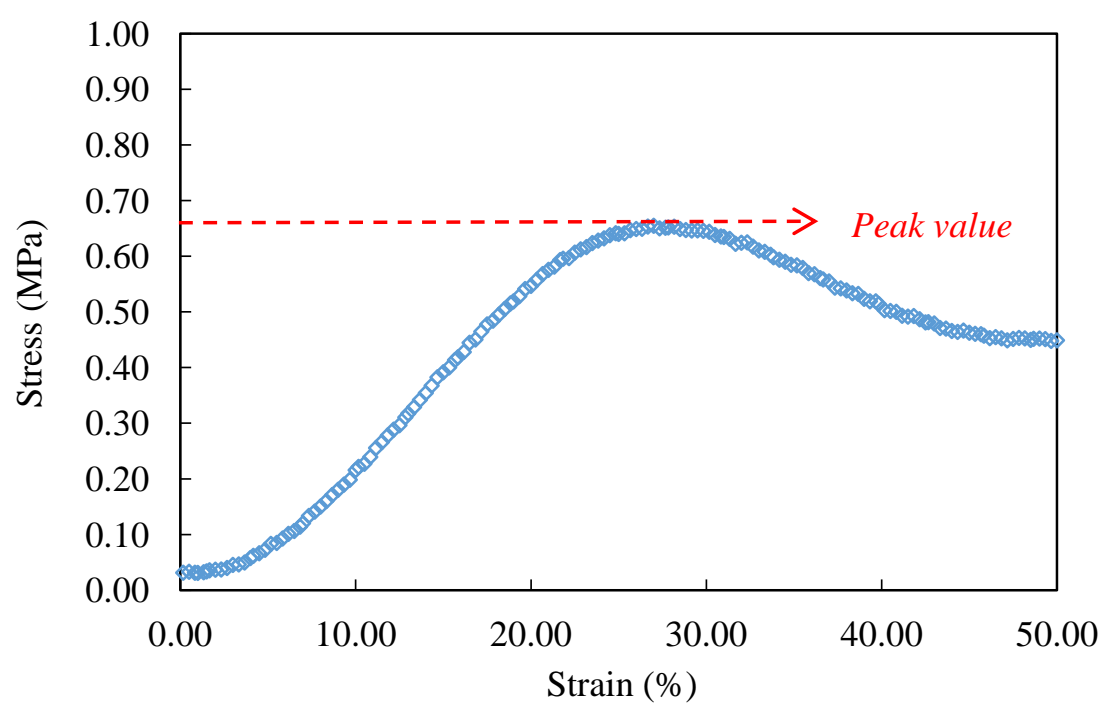

FIGURE 3 Typical test result from direct pull-off test.

\section{RESULTS AND DISCUSSION}

Asphalt binder-aggregate interactions were evaluated under two different types of loading in shear: sinusoidal oscillating, and monotonically increasing displacement. This section presents the results and analyses from these tests.

\section{Quantifying the Level of Interaction}

The interaction between asphalt binder and mineral aggregates is a physico-chemical process that is dictated by the surface properties of both materials. In addition, highly absorptive aggregates such as limestone may selectively adsorb and absorb fractions from the asphalt binder; selective absorption can alter the chemical and physical properties of the binder in the vicinity of the interface. The magnitude of these interactions at the binder-aggregate interface not only depends on the type of materials, but it is also a function of conditioning time and temperature. It was hypothesized that these interactions would influence the properties of the binder in the vicinity of the binder-aggregate interface. However, the conditioning methods used in this study would result in confounding factors, such as aging, that also influence the binder properties. In order to normalize the influence of these confounding factors from the interactions that take place at the interface, it was necessary to use a control interface that would not be susceptible to extensive time and temperature dependent physico-chemical interactions. In this study, a binder-stainless steel interface (control specimens) was used as the basis or datum to normalize for these confounding factors. This was based on the assumption that the interaction between binder and steel is minimal and instantaneous, does not change during conditioning at a constant temperature. This assumption was later verified as discussed in the following paragraphs. Following this concept for quantifying the effect of binder-aggregate interactions on the properties of asphalt binder, the authors defined an interaction parameter $(I P)$ using the complex shear modulus: 


$$
I P=\frac{G_{\text {asphalt-aggregate }}^{*}-G_{\text {asphalt-metal }}^{*}}{G_{\text {asphalt-metal }}^{*}}
$$

Where $G_{\text {asphalt-aggregate }}^{*}$ is the complex shear modulus of the asphalt binder measured in

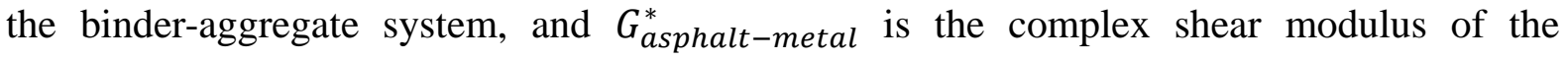
asphalt binder measured in the binder-steel system (control specimen). A positive value of the interaction parameter $(I P)$ indicates that the shear modulus of the binder in the vicinity of the interface has increased due to interaction of the binder with the mineral aggregate (compared to interface with steel) and vice versa. The value of $I P$ is an indicator of the magnitude of interaction, meaning that a stronger interaction will result in a larger value of $I P$. As mentioned before, it is important to emphasize that normalizing the measurements of the aggregate-binder interfaces with the asphalt-metal interfaces to compute the IP was necessary to filter any confounding factors such as aging or steric hardening.

To evaluate the validity of using steel as a control, the binder-steel specimens were fabricated using the initial curing condition of 1 hour at $160^{\circ} \mathrm{C}$. These specimens were then conditioned at $60^{\circ} \mathrm{C}$ for $0,2,10$ and 35 days. To examine the interaction between asphalt binder and steel, the complex shear modulus of the control specimens were measured after conditioning. Table 1 summarizes the test results obtained from testing the control specimens by applying the oscillatory shear load. These results demonstrate that the interaction between binder and steel does not change with conditioning time. As can be seen in Table 1, this has been examined under different loading conditions (temperature and frequency).

The rationale for choosing conditioning temperature of $60^{\circ} \mathrm{C}$ was that higher temperatures would accelerate any physico-chemical interactions. Temperatures higher than $60^{\circ} \mathrm{C}$ were not selected to minimize oxidation and to prevent binder from flowing. The maximum conditioning time of 35 days was selected to allow sufficient time for interactions to occur, while meeting the practical constraints of this research project. Note that some other researchers have indicated that the use of $60^{\circ} \mathrm{C}$ for approximately 30 to 35 days results in binder aging that is similar to the aging simulated by a pressure aging vessel [30-31]. However, in these previous studies the researchers have used thin layers of asphalt binders (typically less than $1 \mathrm{~mm}$ ), whereas, in the present study the thickness of the binder specimens that were in the form of an annular ring, were significantly higher $(10 \mathrm{~mm})$. As a result, it was expected that the binder aging would be limited to the surface of the specimen. In fact, we can see from Table 1 that the results for the complex modulus did not change substantially (or systematically) as a result of the interaction. In summary, the results from the binder-steel system showed that the influence of oxidative aging is small over the conditioning times and temperatures used in this study, and the interaction between binder and steel does not change over time.

The next step was to investigate the influence of conditioning times and temperatures on the properties of the binder in the vicinity of binder-aggregate interface. Test specimens of fresh aggregates and asphalt binder were conditioned at $60^{\circ} \mathrm{C}$ for $0,2,10$ and 35 days. Then, by measuring the complex shear modulus of test specimens after conditioning, the Interaction Parameter was calculated based on Equation 2. Figures 4 and 5 illustrate the time 
dependency of the interaction between an asphalt binder and the two different types of aggregate used in this study (limestone and granite).

Test results demonstrate that interactions at binder-aggregate interface influence the properties of the binder over time. Interestingly, the IP suggests that the binder stiffness first increases and then decreases with time. Although the magnitude of this change was not the same for different combinations, the qualitative trend was similar. It is speculated that the initial increase of the Interaction Parameter is due to the lightweight components (with higher mobility) of the binder being adsorbed or absorbed at the aggregate surface. This agrees with the results reported by $\mathrm{Wu}$ et al. [32]. They used molecular dynamic simulation to demonstrate that the lightweight components in asphalt diffuse faster than the heavyweight components at the initial stage of asphalt-granite interaction. However, when the conditioning time is long enough, all asphalt components eventually reach equilibrium with the interface [33-35], reversing the previous short-term phenomenon. The exceptions to the general trend observed in this study were for the results from the granite specimen tested at the lower frequencies and higher temperatures. It was suspected that the negative IP values could have been due to one or both of the following reasons: (i) anomalous absorption of more polar fractions from the binder, or (ii) the damage in the specimen due to test conditions. A Further investigation, by monitoring the change in shear modulus over the loading cycles, demonstrated that the latter could more likely be the case for the tests conducted at $25^{\circ} \mathrm{C}$; since the complex shear modulus did decrease over loading cycles, indicating damage in the specimen.

Note that the at least three replicates were used for each test under the same set of conditions. The results presented and discussed in the manuscript are based on average of these three results. For stiffness measurement and calculation of the IP, the maximum difference between the individual test values and average value was within $10 \%$ for both steel-binder and aggregate-binder systems. Also the results from Table 1 reflect that the baseline measurements with asphalt-steel interface have an overall standard deviation of $5.7 \%$. This is much smaller than most of the peak average IP values for aggregate-binders' surfaces that are as high as 55\% suggesting that the short-term increase in IP is real. For strength measurement, the variability in the measurements was included in the values presented in Figures 8 and 9, discussed in subsequent sections.

TABLE 1 Effect of Conditioning Time on the Mechanical Behavior (Complex Shear Modulus) of Control Specimens (Asphalt-Steel).

\begin{tabular}{c|ccc|ccc|ccc}
\hline \multirow{2}{*}{$\begin{array}{c}\text { Conditioning } \\
\text { time (days) }\end{array}$} & \multicolumn{6}{c}{ (a) Complex Shear Modulus $G^{*}(\mathrm{Mpa})$} \\
\cline { 2 - 10 } & $0.15^{\circ} \mathrm{C}$ & $1 \mathrm{~Hz}$ & $5 \mathrm{~Hz}$ & $0.1 \mathrm{~Hz}$ & $1 \mathrm{~Hz}$ & $5 \mathrm{~Hz}$ & $0.1 \mathrm{~Hz}$ & $1 \mathrm{~Hz}$ & $5 \mathrm{~Hz}$ \\
0 & 1.01 & 3.15 & 5.05 & 0.67 & 1.88 & 3.63 & 0.66 & 1.64 & 3.08 \\
2 & 0.99 & 3.11 & 5.24 & 0.66 & 1.87 & 3.58 & 0.61 & 1.63 & 3.16 \\
10 & 1.07 & 2.98 & 5.32 & 0.62 & 1.72 & 3.51 & 0.55 & 1.39 & 2.90 \\
35 & 1.02 & 2.71 & 4.59 & 0.62 & 1.60 & 3.19 & 0.57 & 1.37 & 2.80 \\
Average & 1.02 & 2.99 & 5.05 & 0.64 & 1.77 & 3.48 & 0.60 & 1.51 & 2.98 \\
\hline
\end{tabular}




\begin{tabular}{c|ccc|cccc|ccc}
\hline \multirow{2}{*}{$\begin{array}{c}\text { Conditioning } \\
\text { time (days) }\end{array}$} & \multicolumn{5}{c}{ (b) Change in $G^{*}-$ Deviation from average $G^{*}(\%)$} \\
& $0.15^{\circ} \mathrm{C}$ & $1 \mathrm{~Hz}$ & $5 \mathrm{~Hz}$ & $0.1 \mathrm{~Hz}$ & $1 \mathrm{~Hz}$ & $5 \mathrm{~Hz}$ & $0.1 \mathrm{~Hz}$ & $1 \mathrm{~Hz}$ & $5 \mathrm{~Hz}$ \\
0 & -1.50 & 5.51 & -0.01 & 3.73 & 6.24 & 4.45 & 10.56 & 8.77 & 3.19 \\
2 & -2.67 & 4.04 & 3.78 & 2.37 & 5.94 & 2.90 & 1.94 & 7.97 & 5.85 \\
10 & 4.73 & -0.22 & 5.28 & -2.59 & -2.82 & 0.97 & -7.40 & -7.87 & -2.82 \\
35 & -0.56 & -9.34 & -9.06 & -3.52 & -9.36 & -8.31 & -5.09 & -8.87 & -6.22 \\
\hline
\end{tabular}
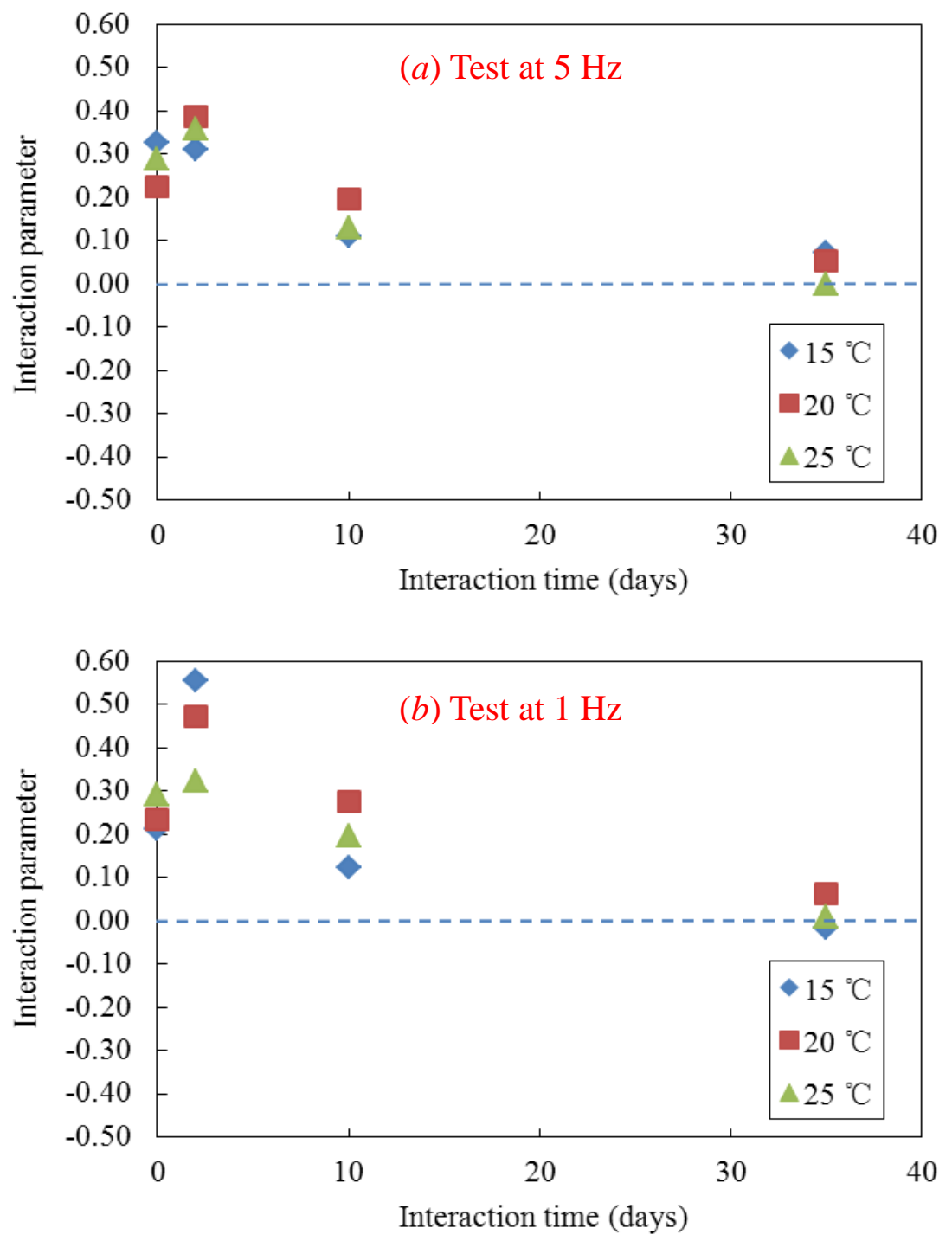


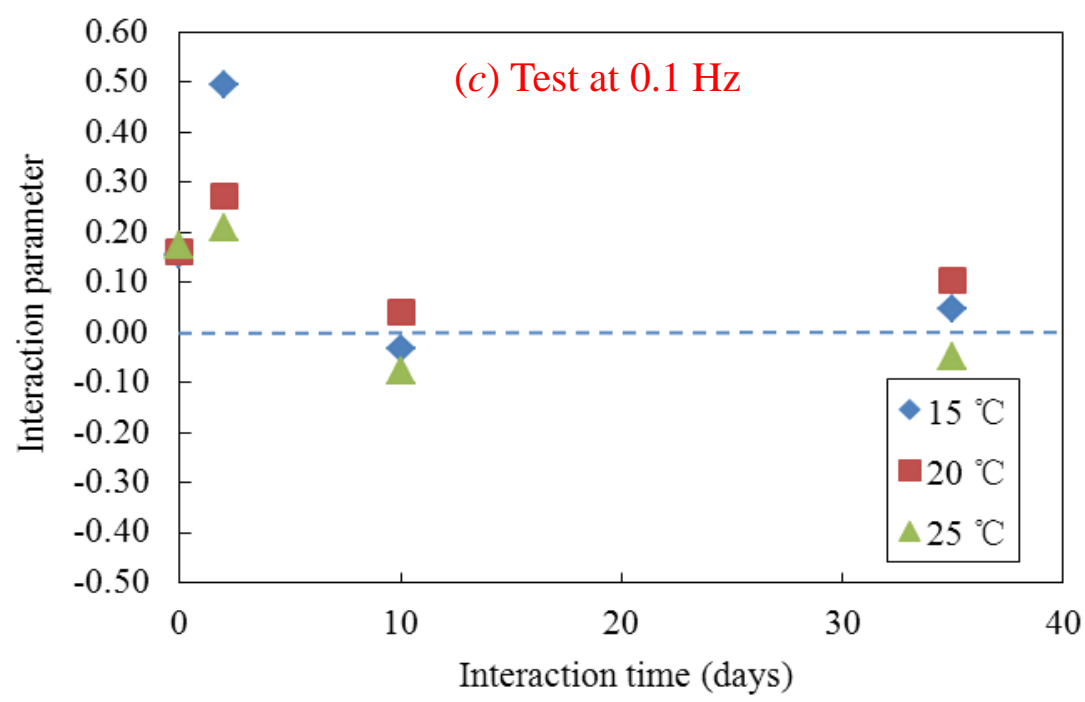

FIGURE 4 Interaction between asphalt binder and limestone measured at three different test temperatures of 15,20 , and $25^{\circ} \mathrm{C}$.
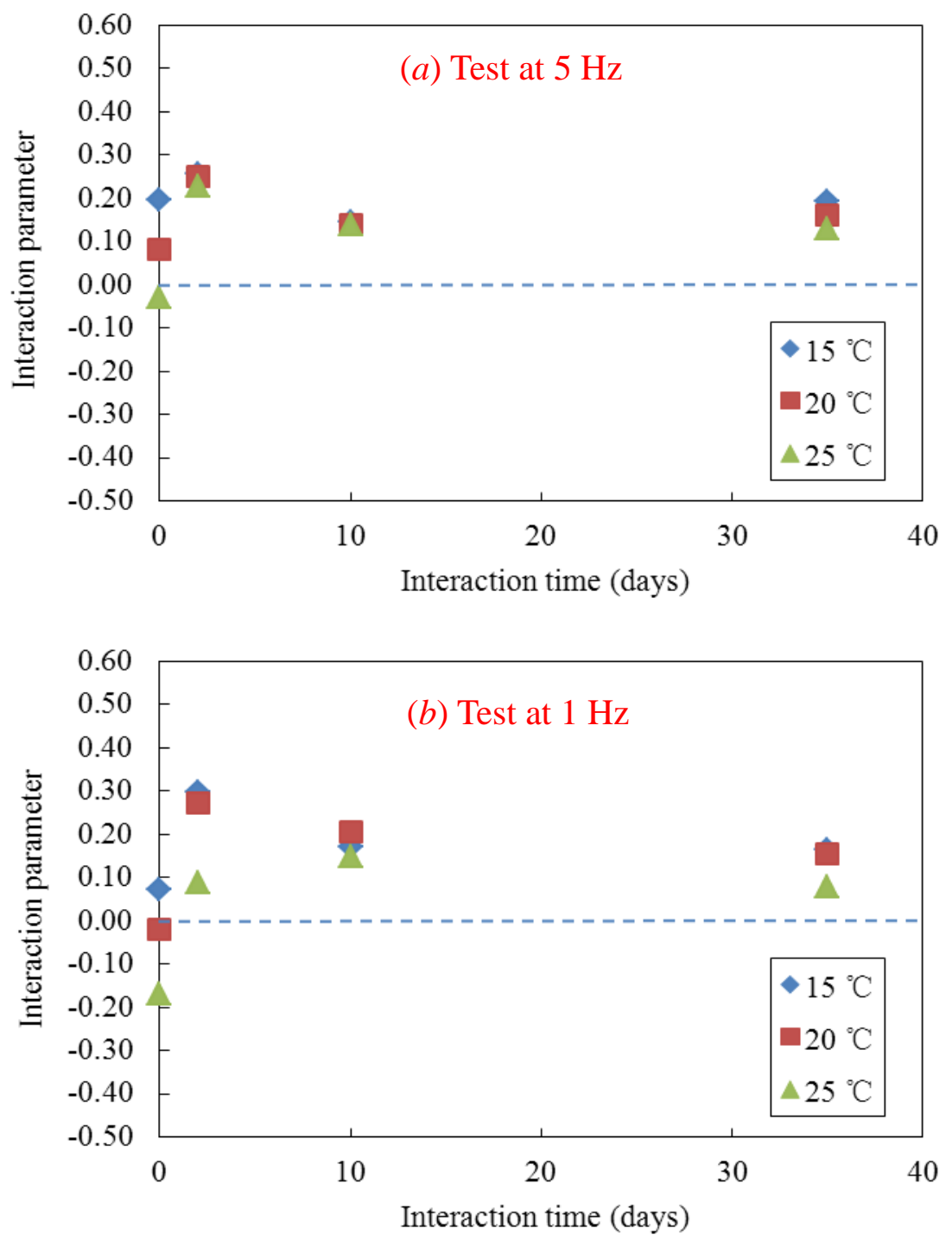


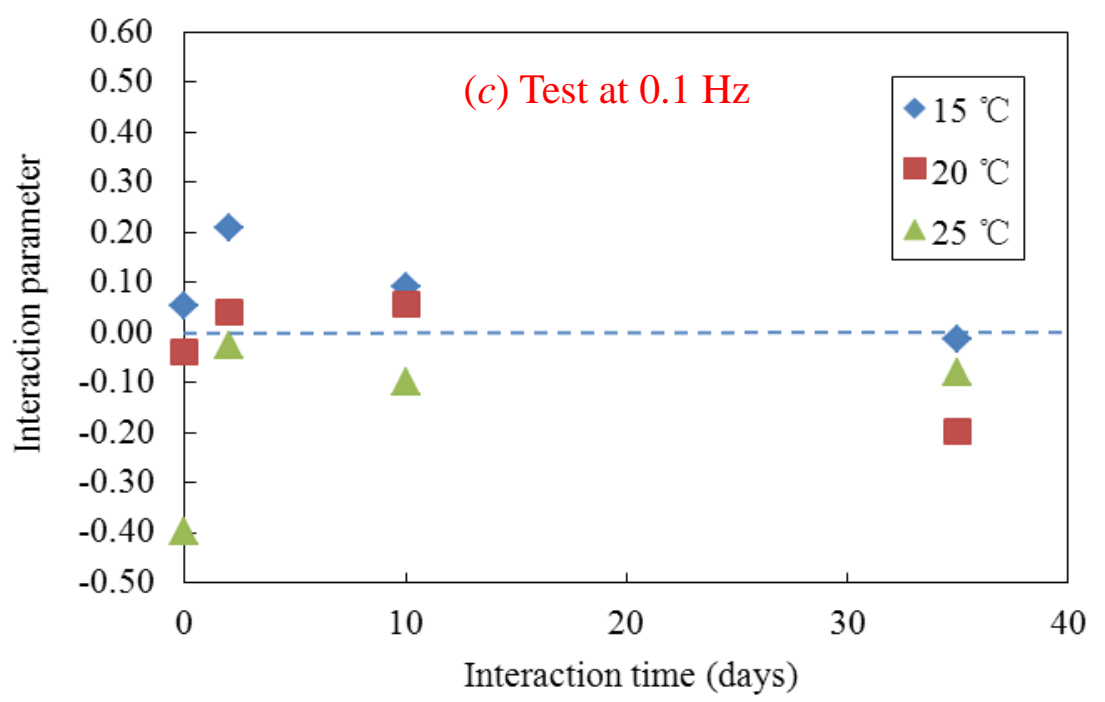

FIGURE 5 Interaction between asphalt binder and granite measured at three different test temperatures of 15,20 , and $25^{\circ} \mathrm{C}$.

\section{Investigating Interfacial Interactions in RAP Aggregates}

In order to investigate the interaction between asphalt binder and RAP aggregates, limestone aggregates were used to artificially produce RAP aggregate surfaces following the procedure discussed earlier. The artificial RAP aggregates were then used to fabricate specimens as before. In order to investigate the effect of curing (mixing) time and temperature on asphalt binder - RAP aggregate interaction or blending of aged and unaged binders, the specimens were prepared and conditioned differently compared to the previous tests. These specimens were prepared at 4 different temperatures $\left(110,130,145\right.$, and $\left.160^{\circ} \mathrm{C}\right)$ and subjected to different curing times (1, 2, and 5 hours) at these temperatures.

Figure 6 shows the influence of curing temperature (at a given curing time) on the interaction between the virgin binder and the RAP aggregate surface. As can be seen, increasing curing temperature to a certain level, can result in stronger interaction between fresh asphalt binder and artificial RAP aggregate. This observation was independent of the test frequency and test temperature. This finding agrees with Bowers et al.'s work in which they found that mixing temperature plays a significant role in the increase of the blend ratio, from $59 \%$ at $130^{\circ} \mathrm{C}$ to $70 \%$ at $180^{\circ} \mathrm{C}$. Mixing at a higher temperature of $180^{\circ} \mathrm{C}$ had no noticeable effect on the fine RAP aggregate [36]. Figure 6 shows that for the curing time of 2 hours, curing temperatures of 145 and $160^{\circ} \mathrm{C}$ will result in similar degree of interaction. However, the interactions at 110 and $130^{\circ} \mathrm{C}$ were significantly weaker than the ones at 145 and $160^{\circ} \mathrm{C}$.

Figure 7 shows the influence of the curing time (at a given temperature) on the interaction between the virgin binder and RAP aggregate surface. As can be seen, at a constant temperature, properly extending curing time can enhance the interaction. These factors are important when considering appropriate curing time and temperature, particularly when a combination of RAP and WMA is being used. 


\section{Interfacial Shear Performance}

After conducting oscillatory tests to measure the level of interaction, pull-off tests were conducted to measure the bonding shear strength of the interface. As described earlier, the pull-off test was performed by applying monotonically increasing displacement at a rate of 1 $\mathrm{mm} / \mathrm{s}$. Plotting stress-strain curve for this test, the pull off strength of the binder as influenced by the interfacial interactions was obtained. Figure 3 illustrates a typical test result from the direct pull-off test under monotonic loading. The peak of the stress-strain curve, referred to as the bonding shear strength, was used as an indicator of the effect of interfacial interactions on the shear performance of the binder.

The measured interfacial shear strength for the specimens made with fresh mineral aggregates, and conditioned for different periods of time, showed a similar trend to the one observed for the IP (from oscillatory test). The interfacial shear strength for specimens made with the artificial RAP aggregates were also measured and depicted in Figures 8 and 9. Figure 8 demonstrates the effect of curing temperature, and Figure 9 illustrates the effect of curing time on the interfacial shear strength.
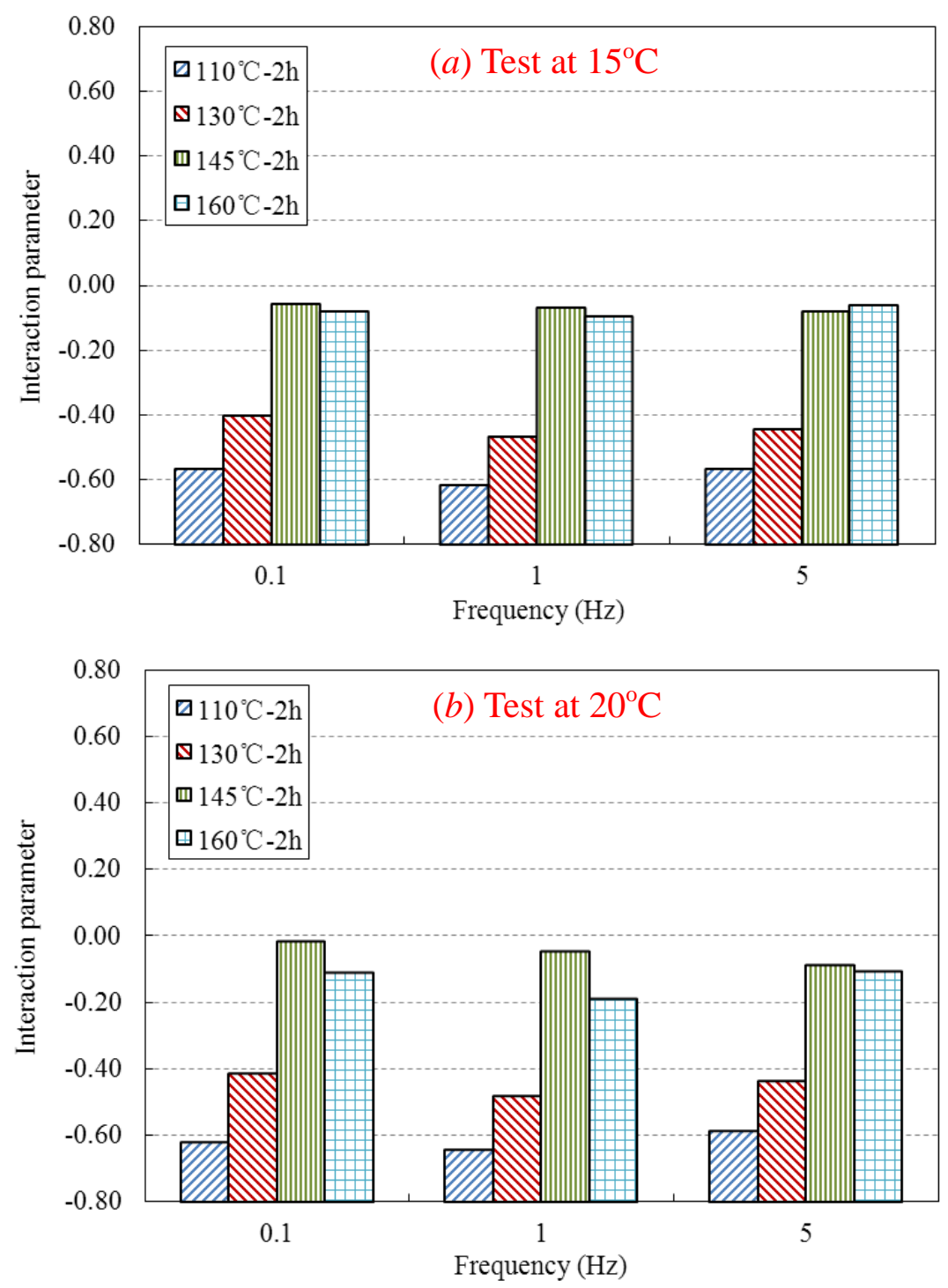


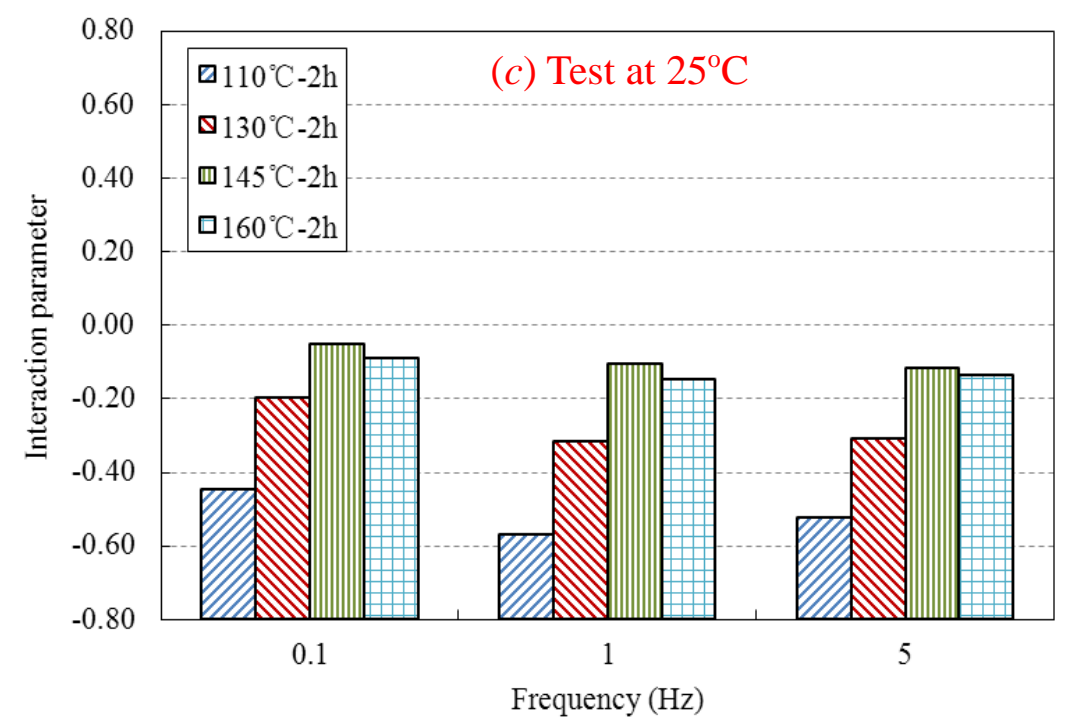

FIGURE 6 Effect of mixing (curing) temperature on interaction between fresh binder and artificial RAP aggregate.
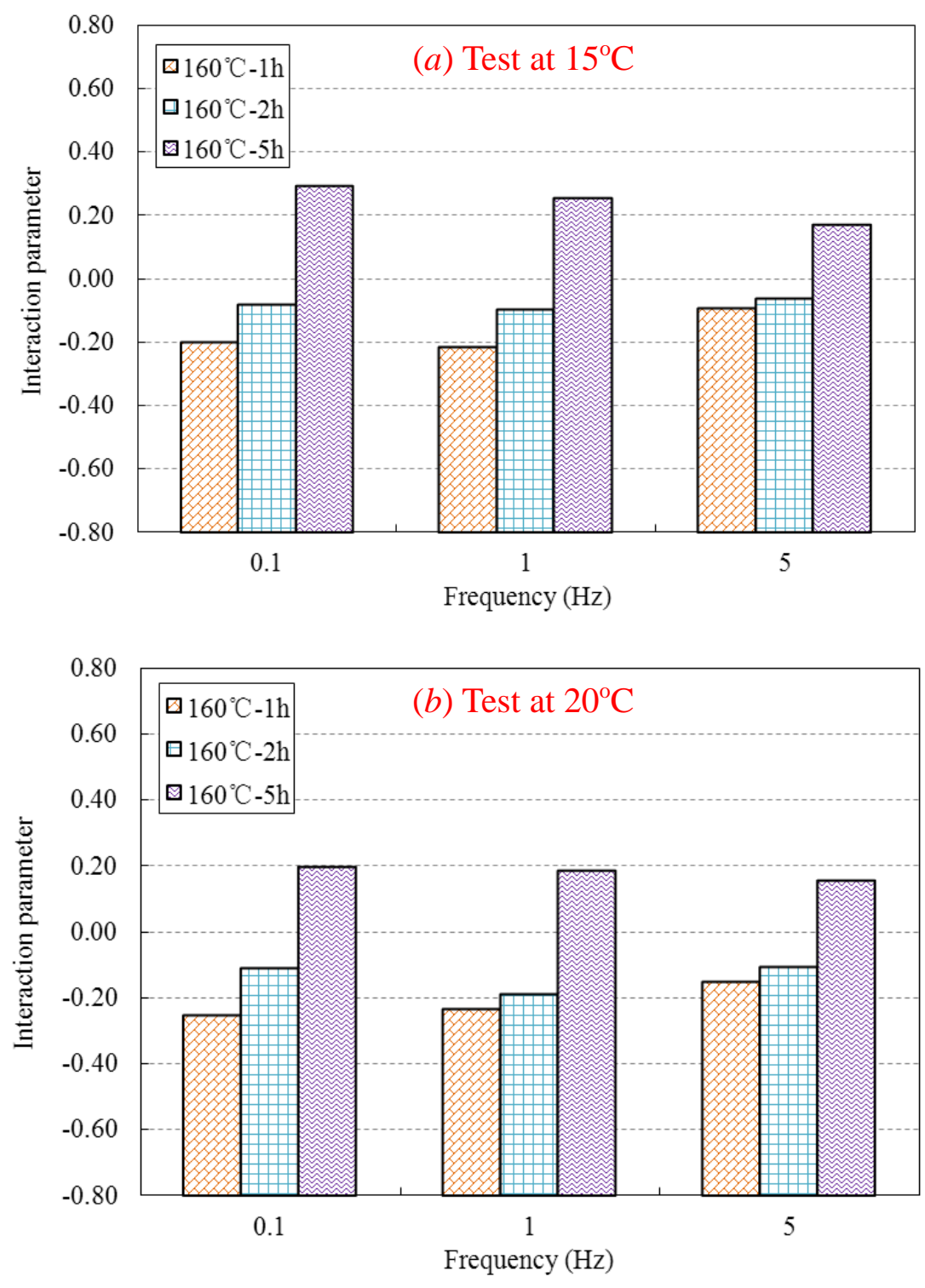


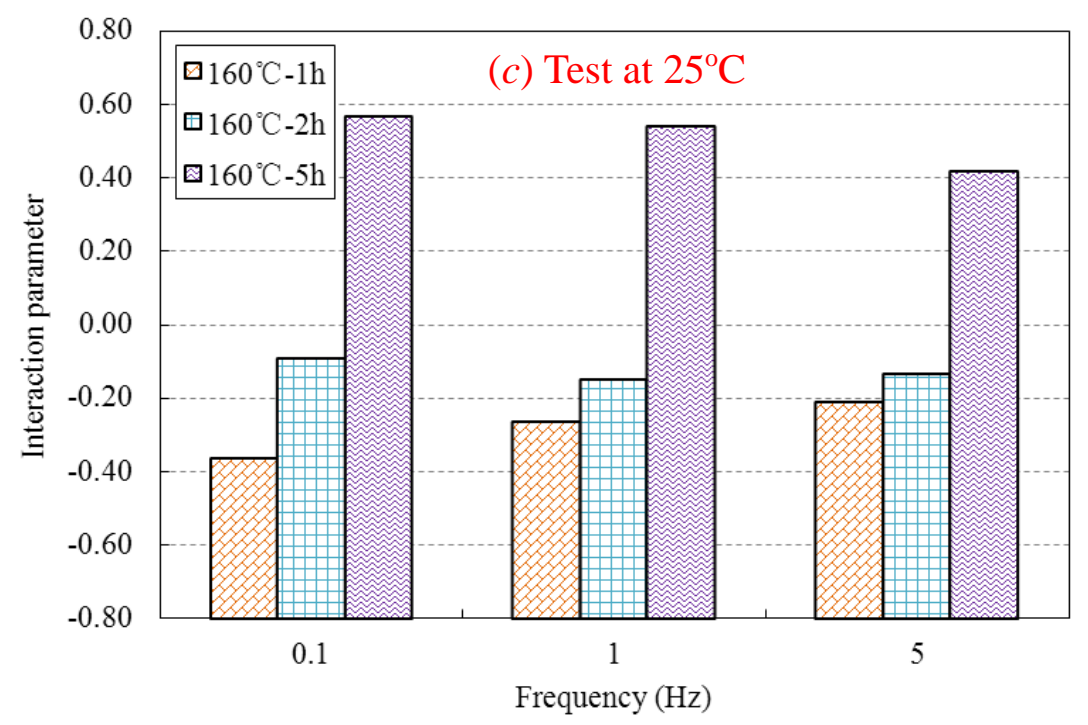

FIGURE 7 Effect of mixing (curing) time on interaction between fresh binder and artificial RAP aggregate.

Figure 8 shows the test results for the RAP specimens cured for 2 hours at different temperatures. These results demonstrate the effect of curing temperature and shows that increasing curing temperature can enhance shear strength of the binder. This is consistent with the trend previously observed for Interaction Parameter. This finding further reinforces the observation that the mixing temperature plays an important role in production of mixtures with RAP, and should be carefully monitored. These results also suggest that the production of RAP mixtures at lower temperatures by means of warm mix additives may reduce the integrity of the mixture, at least in the short-term.

Figure 9 illustrates the effect of curing time on the interfacial shear strength. These results show that extending curing time can enhance shear resistance. This observation is consistent with results obtained from oscillatory test (the trend for $I P$ ). Similar to the results for Interaction Parameter, five hours curing time at $160^{\circ} \mathrm{C}$ showed the highest value for the interfacial shear strength. However, one should also consider the long term performance of the mixture as well as the economical and environmental issues associated with extended curing at an elevated temperature.

Unlike IP, which is normalized for the influence of aging, the results in Figures 8 and 9 for shear strength are not normalized with respect to the steel-binder results. As such, it is possible to argue that the increases in shear strength observed over time are due to aging of the binder and not due to interaction or intermingling between the aged (RAP) and fresh binder. However, this is unlikely to be the case for two reasons. First, the normalized results for IP that normalizes for the contribution of aging shows a change in stiffness that is consistent with the change in strength observed in Figures 8 and 9. Second, results from Table 1 show that the influence of aging is minimal over the properties of the binder in this setup. 


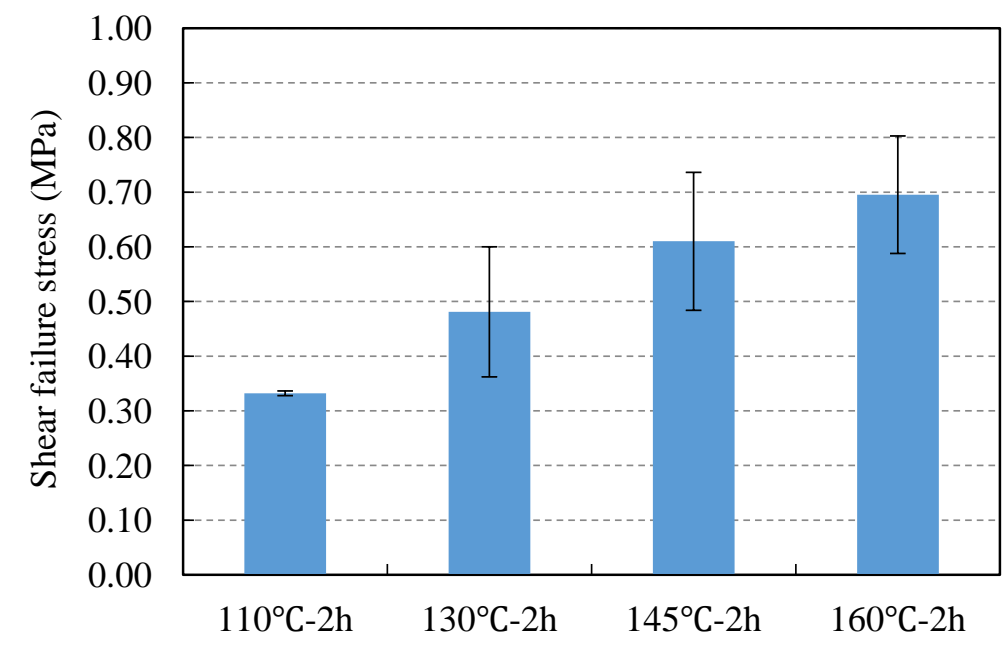

FIGURE 8 Effects of mixing (curing) temperature on the bonding shear strength of the interface between asphalt binder and artificial RAP aggregate.

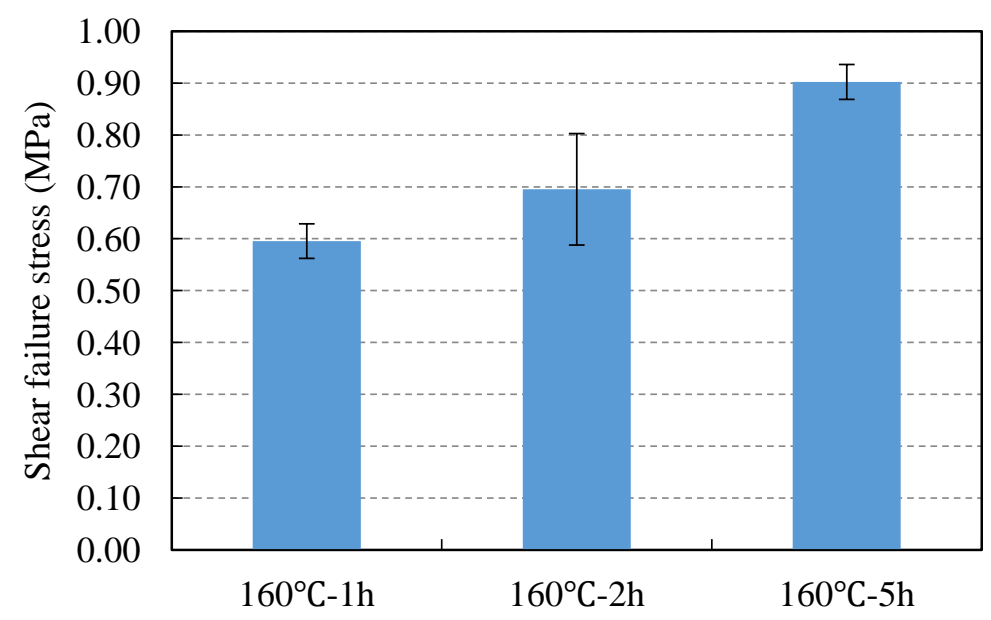

FIGURE 9 Effects of mixing (curing) time on bonding shear strength of the interface between asphalt binder and artificial RAP aggregate.

As can be seen in Figures 8 and 9, the trend for the shear strength was similar to the one observed for the IP. This indicates that there might be a good correlation between the $I P$ and the shear performance (bonding shear strength). An investigation of these two properties showed that there is a strong linear correlation between $I P$ and shear strength, Figure 10. This implies that the interaction between aggregate and asphalt binder can lead to an increase in both stiffness and strength of the asphalt binder in the vicinity of the interface. Therefore, an increase in binder stiffness due to interfacial interaction, which might result in an increase in induced stresses under traffic loadings, may not necessarily adversely influence the shear performance of the mixture. Of course, this correlation is empirical and based on very limited data and will need to be investigated further in future studies. 

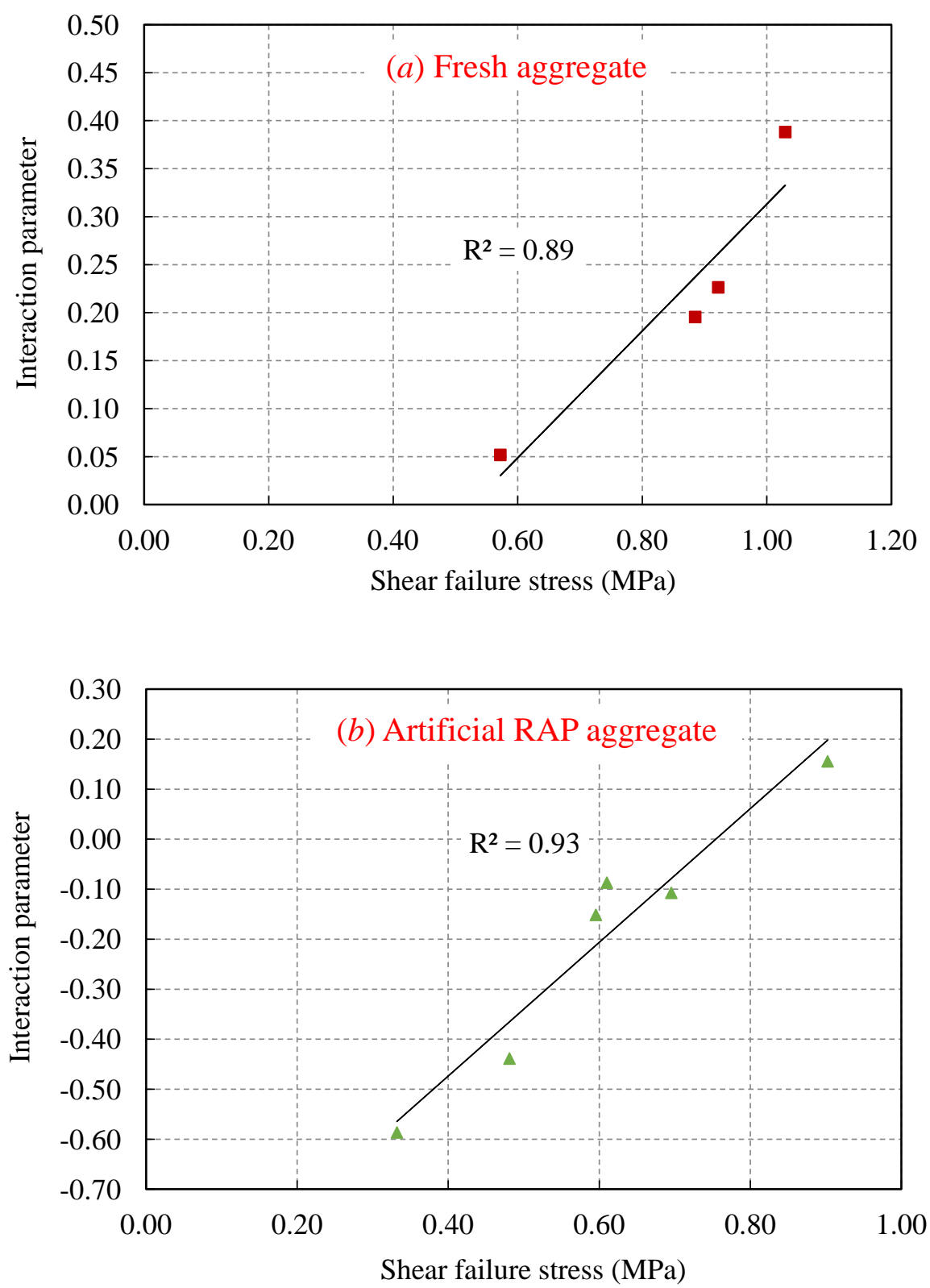

FIGURE 10 Correlation between interaction parameter (at $5 \mathrm{~Hz}$ ) and interfacial shear strength, at $20^{\circ} \mathrm{C}$.

\section{SUMMARY OF FINDINGS AND CONCLUDING REMARKS}

In order to study the interactions between asphalt binder and mineral aggregates, an interfacial test geometry was developed. The effect of interfacial interactions was evaluated under two different modes of loading in shear: sinusoidal oscillation and monotonically increasing. An Interaction Parameter (IP) was proposed based on interfacial response under sinusoidal loading. The results demonstrated that this interfacial test geometry can be used to evaluate the degree of interaction between asphalt binder and aggregate. Employing the developed methodology, this research investigated the effect of aggregate type, conditioning time, and conditioning temperature on the binder-aggregate interaction. The followings are the other main findings from this study: 
- The influence of binder-aggregate interaction on the properties of the binder is dependent on the duration of interaction. It was observed that typically the binder-aggregate interaction initially increases the stiffness of the binder and then decreases with time.

- The magnitude of this change was dependent on the binder-aggregate pair. The limestone aggregate typically had a stronger interaction with asphalt binder compared to granite. Note that the magnitude of this change is also dependent on the thickness of the annular ring specimen used in the tests. Although this factor (thickness) was held constant for all the tests in this study, the sensitivity of the measurements can be increased or decreased by using specimen of lower or higher thickness.

- The result from this study using a laboratory simulated RAP aggregate surface quantitatively demonstrates that the mixing time and temperature significantly influence the interfacial properties. Higher curing temperature or longer curing time can produce stronger interaction between fresh asphalt binder and a RAP aggregate surface. Test results for two hours of curing time showed that the increase in temperature up to $145^{\circ} \mathrm{C}$ improved blending and interfacial properties.

- There is a correlation between interaction parameter and interfacial shear performance. These data, although limited, suggest that the interaction between aggregate and asphalt binder can increase both stiffness and strength of the asphalt binder in the vicinity of the interface.

Existing literature suggests that the properties of the binder significantly influence the properties of the mixture and are also influenced by interactions with mineral aggregates. Typically, statistical or computational models that relate binder properties to mixture performance rely on the measured bulk properties of the binder without accounting for the change in these properties due to the binders' interaction with mineral aggregates. The findings from this study, addresses this important gap. For example, the stiffness of the binder measured as a bulk property can be corrected using the appropriate IP (depending on the conditioning time and environment) as a correction factor in modeling the response of the composite. In fact, the proposed approach can also be extended to other similar composites and used to determine indices to correct for the stiffness of a matrix (in this context binder) in the vicinity of an inclusion (in this context aggregate) when the two components have strong physico-chemical interactions.

Finally, in the context of recycled asphalt in production of new mixes, the literature lacks clarity regarding the time-temperature conditions that result in mixing of aged and fresh binder. The proposed approach can be used to quantitatively establish the minimum time and temperature conditions that are required to ensure complete comingling between the aged binder and the fresh binder (matrix). This approach can also be used to quantitatively evaluate the influence of agents such as rejuvenators on the blending of RAP and virgin binders or similar agents used in other composite materials. 


\section{ACKNOWLEDGMENTS}

The authors are grateful from China Scholarship Council (Grant number: 201306120187) and National Science Fund for Distinguished Young Scholars of China (Grant number: 51225803) for their financial support. This study was also partially supported through National Science Foundation of the United States through grant NSF CMMI-1053925. 


\section{REFERENCES}

[1] Huang SC, Robertson RE, Branthaver JF, Petersen JC. Impact of lime modification of asphalt and freeze-thaw cycling on the asphalt-aggregate interaction and moisture resistance to moisture damage. Journal of Materials in Civil Engineering, 2005, 17(6), 711-718.

[2] Little DN, Petersen JC. Unique effects of hydrated lime filler on the performance-related properties of asphalt cements: Physical and chemical interactions revisited. Journal of Materials in Civil Engineering, 2005, 17(2): 207-218.

[3] Lesueur D, Petit J, Ritter HJ. The mechanisms of hydrated lime modification of asphalt mixtures: a state-of-the-art review. Road Materials and Pavement Design. 2013, 14(1): $1-16$.

[4] Zhu XY, Wang XF, Yu Y. Micromechanical creep models for asphalt-based multi-phase particle-reinforced composites with viscoelastic imperfect interface. International Journal of Engineering Science. 2014, 76: 34-46.

[5] Guo M, Tan YQ, Zhou SW. Multiscale test research on interfacial adhesion property of cold mix asphalt. Construction and Building Materials. 2014, 68: 769-776.

[6] Bhasin A. Development of methods to quantify bitumen-aggregate adhesion and loss of adhesion due to water. Texas A\&M University, College Station. 2006.

[7] Tan YQ, Guo M. Micro- and nano-characteration of interaction between asphalt and filler. Journal of Testing and Evaluation. 2014, 42(5): 1089-1097.

[8] Hesami E, Birgisson B, Kringos N. Numerical and experimental evaluation of the influence of the filler-bitumen interface in mastics. Materials and Structures. 2014, 47(8): 1325-1337.

[9] Miomir Miljkovic, Martin Radenberg. Fracture behaviour of bitumen emulsion mortar mixtures. Construction and Building Materials. 2014, 62: 126-134.

[10] Nahar SN, Mohajeri M, Schmets AJM, Scarpas A, van de Ven MFC, Schitter G. First observation of blending-zone morphology at interface of reclaimed asphalt binder and virgin bitumen. Transportation Research Record: Journal of the Transportation Research Board. 2013, 2370: 1-9.

[11] Mohajeri M, Molenaar AAA, Van de Ven MFC. Experimental study into the fundamental understanding of blending between reclaimed asphalt binder and virgin bitumen using nanoindentation and nano-computed tomography. Road Materials and Pavement Design. 2014, 15(2): 372-384.

[12] Zhao S, Nahar SN. Schmets AJM. Huang BS. Shu X. Scarpas T. Investigation on the microstructure of recycled asphalt shingle binder and its blending with virgin bitumen. Road Materials and Pavement Design. 2015, 16(1): 21-38.

[13] Ghabchi R, Singh D, Zaman M. Evaluation of moisture susceptibility of asphalt mixes containing RAP and different types of aggregates and asphalt binders using the surface free energy method. Construction and Building Materials. 2014, 73: 479-489.

[14] Tan YQ, Guo M. Using surface free energy method to study the cohesion and adhesion of asphalt mastic. Construction and Building Materials. 2013, 47: 254-260. 
[15] Wei JM, Dong FQ, Li YN, Zhang YZ. Relationship analysis between surface free energy and chemical composition of asphalt binder. Construction and Building Materials. 2014, 71: 116-123.

[16] Clopotel C, Velasquez R, Bahia H. Measuring physico-chemical interaction in mastics using glass transition. Road Materials and Pavement Design. 2012, 13: 304-320.

[17] Tan YQ, Guo M. Interfacial thickness and interaction between asphalt and mineral fillers. Materials and Structures. 2014, 47: 605-614.

[18] Taylor R. Surface interaction between bitumen and mineral fillers and their effects on the rheology of bitumen-filler mastics. University of Nottingham, Nottingham, 2007.

[19] Tan YQ, Guo M. Study on the phase behavior of asphalt mastic. Construction and Building Materials. 2013, 47: 311-317.

[20] Ribeiro RC, Correia JCG, Seid PR. The influence of different minerals on the mechanical resistance of asphalt mixtures. Journal of Petroleum Science and Engineering. 2009, 65: 171-174.

[21] Horgnies M, Darque-Ceretti E, Fezai H, Felder E. Influence of the interfacial composition on the adhesion between aggregates and bitumen: Investigations by EDX, XPS and peel tests. International Journal of Adhesion \& Adhesives. 2011, 31: 238-247.

[22] Davis C, Castorena C. Implications of physico-chemical interactions in asphalt mastics on asphalt microstructure. Construction and Building Materials. 2015, 94: 83-89.

[23] Rinaldini E, Schuetz P, Partl MN, Tebaldi G, Poulikakos LD. Investigating the blending of reclaimed asphalt with virgin materials using rheology, electron microscopy and computer tomography. Composites Part B-Engineering. 2014, 67: 579-587.

[24] Mallick RB, Kandhal PS, Bradbury RL. Using warm-mix asphalt technology to incorporate high percentage of reclaimed asphalt pavement material in asphalt mixtures. Transportation Research Record: Journal of the Transportation Research Board. 2008, 2051: 71-79.

[25] Shu X, Huang BS, Shrum ED, Jia XY. Laboratory evaluation of moisture susceptibility of foamed warm mix asphalt containing high percentages of RAP. Construction and Building Materials. 2012, 35: 125-130.

[26] Guo NS, You ZP, Zhao YH, Tan YQ, Diab A. Laboratory performance of warm mix asphalt containing recycled asphalt mixtures. Construction and Building Materials. 2014, 64: 141-149.

[27] Zhao S, Huang BS, Shu X, Woods M. Comparative evaluation of warm mix asphalt containing high percentages of reclaimed asphalt pavement. Construction and Building Materials. 2013, 44: 92-100.

[28] Hill B, Behnia B, Buttlar WG, Reis H. Evaluation of warm mix asphalt mixtures containing reclaimed asphalt pavement through mechanical performance tests and an acoustic emission approach. Journal of Materials in Civil Engineering. 2013, 25(12): 1887-1897.

[29] Motamed A, Bahia H. Influence of test geometry, temperature, stress level, and loading duration on binder properties measured using DSR. Journal of Materials in Civil 
Engineering. 2011, 23(10): 1422-1432.

[30] Arega ZA, Bhasin A, De Kesel T. Influence of extended aging on the properties of asphalt composites produced using hot and warm mix methods. Construction and Building Materials. 2013, 44: 168-174.

[31] Glover CJ, Davison RR, Domke CH, Ruan Y, Juristyarini P, Knorr DB, Jung SH. Development of a new method for assessing asphalt binder durability with field validation. Texas Transportation Institute. 2005.

[32] Wu GZ, He L, Chen DY. Sorption and distribution of asphaltene, resin, aromatic and saturate fractions of heavy crude oil on quartz surface: Molecular dynamic simulation. Chemosphere. 2013, 92: 1465-1471.

[33] Petersen JC. Chemical composition of asphalt as related to asphalt durability: state of the art. Transportation Research Record: Journal of the Transportation Research Board. 1984, 999: 13-30.

[34] Luo R, Lytton RL. Selective absorption of asphalt binder by limestone aggregates in asphalt mixtures. Journal of Materials in Civil Engineering. 2013, 25(2): 219-226.

[35] Clopotel C, Bahia H. The effect of bitumen polar groups adsorption on mastics properties at low temperatures. Road Materials and Pavement Design. 2013, 14(1): 38-51.

[36] Bowers BF, Moore J, Huang BS, Shu X. Blending efficiency of reclaimed asphalt pavement: an approach utilizing rheological properties and molecular weight distributions. Fuel. 2014, 135: 63-68. 

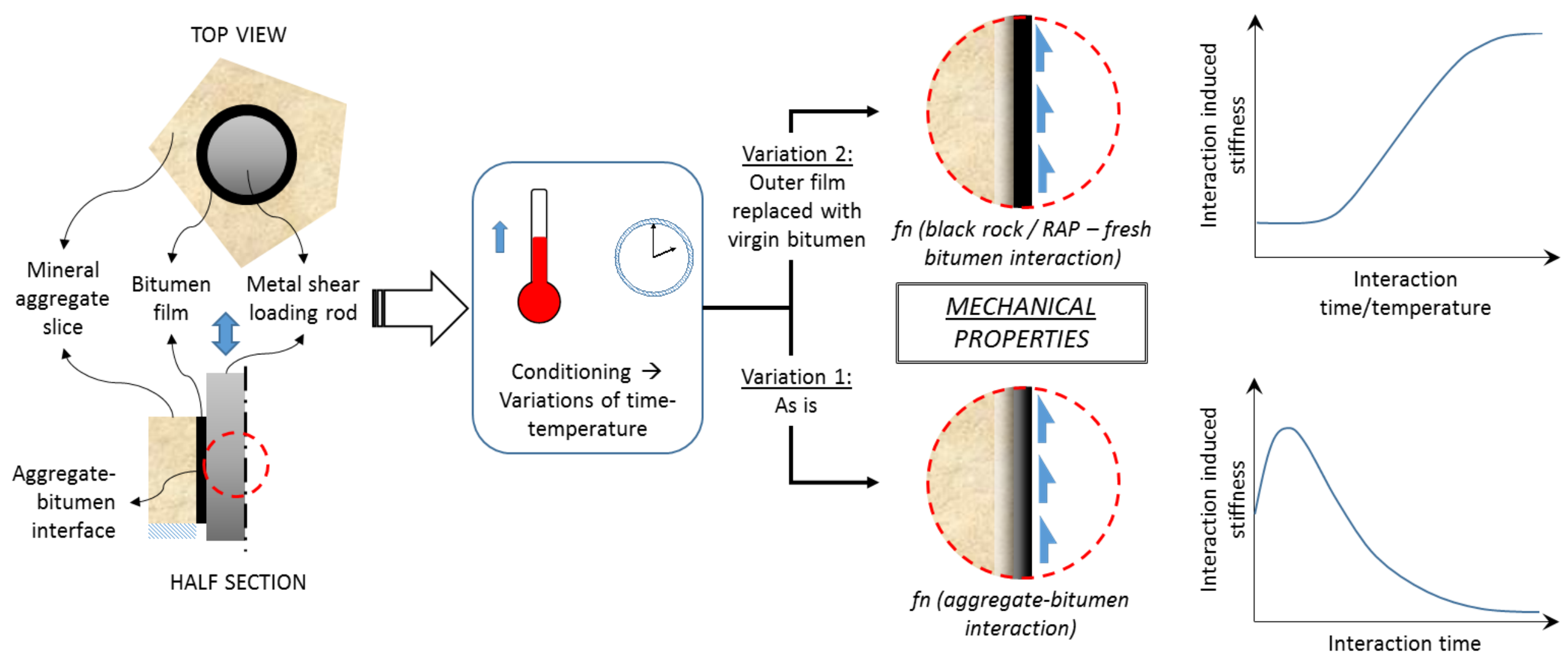